\title{
Detection of dysplasia in Barrett's oesophagus: Are there impending optical and spectroscopic solutions?
}

\author{
Upchurch E ${ }^{1 *}$, Old OJ ${ }^{2}$, Lloyd GR ${ }^{1}$, Isabelle M ${ }^{1}$, Kendall $C^{1}$, Shetty G ${ }^{1}$, Pavlou A ${ }^{1}$, Shepherd $N^{3}$ and Barr $H^{2}$ \\ ${ }^{1}$ Biophotonics Unit, Leadon House, Gloucestershire Royal Hospital, Great Western Road, Gloucester, UK \\ ${ }^{2}$ Department of Upper GI Surgery, Gloucestershire Royal Hospital, Great Western Road, Gloucester, UK \\ ${ }^{3}$ Department of Histopathology, Cheltenham General Hospital, Sandford Road, Cheltenham, UK
}

\begin{abstract}
The incidence of Barrett's oesophagus and oesophageal adenocarcinoma is increasing in Western countries. The outcome for patients with oesophageal cancer is extremely poor with only $15.1 \%$ of patients surviving for 5 years. The dismal outcome is largely due to late diagnosis which eliminates many patients from effective treatment.

Oesophageal adenocarcinoma is often preceded by the development of dysplasia in a segment of Barrett's oesophagus. With the current surveillance strategies, it is extremely difficult to not only visualise areas of dysplasia, but also to accurately identify their morphological and architectural changes during histopathological diagnosis. Consensus statements recommend mucosal resection for dysplastic change in the oesophagus, thereby, preventing the development of adenocarcinoma. This strategy requires improved diagnostic tools that can reliably distinguish patients with dysplasia.

Years of research have looked at a variety of different modalities that may aid with the current dilemma of difficulties in diagnosing dysplasia. This review looks at the modalities under development and analyses their advantages and the part they may well play in the future. It also looks at the future avenues that could be explored to aid in the understanding of the disease and to improve the outcomes.
\end{abstract}

\section{Introduction}

The recent increase in the incidence of Barrett's oesophagus and oesophageal adenocarcinoma, especially in Western countries, has fuelled the sharp rise in the number of studies attempting to understand this disease as well as the development of improved diagnostic modalities that can detect its very early stages and even predict those at greatest risk of disease progression.

Current diagnostic techniques and advancements in surgery with a move to a minimally invasive approach have failed to impact on the mortality rates for oesophageal adenocarcinoma with the 5 year survival floundering at $15.1 \%$, making this the fifth leading cause of cancer-related death in men worldwide [1]. The paramount focus must, therefore, be on the improved detection and diagnosis of the early changes of disease that will facilitate early treatment and will, therefore, revolutionize the mortality statistics.

\section{Barrett's oesophagus}

Barrett's oesophagus, originally described in 1950 [2], is an acquired condition, characterised by the replacement of normal squamous epithelium by columnar epithelium in a process termed metaplasia. It is a premalignant condition that predisposes to the development of oesophageal adenocarcinoma, although the overall risk is small with the conversion rate of oesophageal adenocarcinoma from Barrett's oesophagus being $0.5 \%$ per year [3]. It has been established that adenocarcinoma develops through a multi-step morphological pathway, characterised by increasing grades of dysplasia [4], and it is the presence and grade of dysplasia that is currently the only marker that is able to delineate those at a higher risk of progression to adenocarcinoma.
This is, however, not a perfect method. The natural history of high grade dysplasia remains debatable with certain factors correlated with a higher risk of progression, including central obesity, length of Barrett's segment, insulin resistance and serum levels of leptin [5]. The natural course of low grade dysplasia is more hotly contested with some evidence indicating that this can regress, although this may be related to initial inaccurate diagnosis [6]. Persistent low grade dysplasia was, however, associated with disease progression [7].

\section{Dysplasia}

The recognition of dysplasia is extremely complex. The major difficulty is our ability to detect and biopsy the areas with dysplasia. Although metaplasia is apparent macroscopically at endoscopy, areas of dysplasia are not always identifiable. The current protocol is, thus, for random biopsies from each quadrant of the oesophagus at every $1-2 \mathrm{~cm}$ interval in a macroscopically columnar lined area, known as the Seattle Protocol. Even if properly adhered to, significant pathology can be missed; $40 \%$ of resections undertaken for presumed high grade dysplasia had an occult malignancy detected during histological analysis which had not been identified on the preoperative diagnostic endoscopy $[8,9]$. Additional studies indicate that $34 \%$ of early stage

Correspondence to: Emma Upchurch, Clinical Research Fellow, Biophotonics Unit, Leadon House, Gloucestershire Royal Hospital, Gloucester, UK, Tel: +44 300422 5895, E-mail: em_upchurch@hotmail.com

Key words: autofluorescence, Barrett's oesophagus, dysplasia, oesophageal adenocarcinoma, spectroscopy

Received: May 02, 2016; Accepted: June 07, 2016; Published: June 10, 2016 
oesophageal cancers (both squamous and adenocarcinoma) had not been recognised in preceding endoscopies [10].

The problem does not end there. Even if areas with dysplasia are randomly selected for biopsy, there can be considerable difficulty in determining the degree of abnormality present. Dysplasia is characterised by multiple morphological changes and it is often the degree of the abnormalities that determines not only if dysplasia is present, but also its grade (Figure 1). The criteria for a diagnosis of low grade dysplasia includes preserved nuclear polarity, nuclear heterogenicity and margination, few mitoses and decreased numbers of transition to adjacent glandular epithelium [11]. Architectural changes should be absent or minimal.

With a complex array of changes, it is hardly surprising that there is a high degree of intra- and inter-observer variability [12-14] in assigning a grade to these patients. The assessment is highly subjective and dependent on experience. It is, however, vitally important as the diagnosis of low grade dysplasia documents a watershed transition in the course of the disease and has significant management implications.

Parallel to the morphological changes seen in dysplasia, genetic alterations occur which alter gene expression and, subsequently, the regulation of the cell cycle. There is evidence, for example, that p16 hypermethylation is an early predictor of progression in Barrett's oesophagus, especially in low grade dysplasia [15]. Extensive evidence shows that p53 overexpression is seen in both cancerous and high grade dysplasia and is, thus, predictive of progression [16]. This could be an excellent predictive tool when its overexpression is detected by immunohistochemistry [17]. Due to the complexity of the control of the cell cycle and the amount of genetic alterations that can occur, it is likely that mutations will vary between patients and there may not be a single trigger that will be able to explain, nor predict, progression, but rather an accumulation of changes that will ultimately push the cell towards carcinoma.

Dysplasia is, nevertheless, despite its problems, the best method that we currently have at our disposal to identify risk of progression to adenocarcinoma and, thus, to identify patients who would benefit from early, minimally invasive endoscopic intervention. Consensus statements generated through a Delphi process $[3,18]$ recommend that endoscopic ablation or resection is undertaken in the presence of established dysplastic degeneration, making the accurate assessment of dysplasia a vital process. This logically leads to improved outcomes as a cohort of patients will be able to avoid the development of oesophageal adenocarcinoma and the major undertaking of an oesophagectomy.

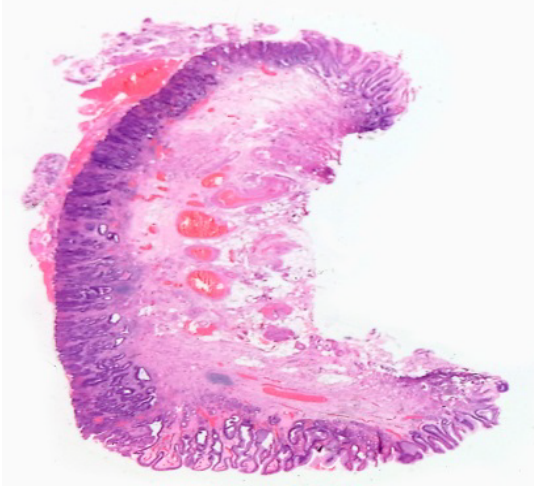

Figure 1. Focal area of high grade dysplasia in an endoscopic resection specimen.

\section{Identifying dysplasia}

Endoscopic surveillance and biopsy is at present the mainstay for identifying dysplasia in Barrett's oesophagus. Endoscopic screening for Barrett's oesophagus is, at present, being suggested for men aged 60 years with prolonged ( $>10$ years) reflux symptoms [3] as their risk of progression to dysplasia and adenocarcinoma is greatest. Population based screening is not recommended due to the low rate of conversion of Barrett's oesophagus to adenocarcinoma [19]. Controversy does, however, remain as to the frequency of surveillance endoscopy and which patients require more intensive surveillance and in whom it can be stopped. A large RCT is currently underway to help solve this dilemma [20].

Surveillance has been shown to be beneficial as surveillance leads to diagnosis of oesophageal adenocarcinoma at an earlier stage and, hence, leads to improved survival [21]. The outcomes were better when compared to patients diagnosed outside of a screening programme and dramatically better than those who had already become symptomatic [22].

The main quandary is how to bring forward the diagnosis of dysplasia to allow earlier, and ultimately minimally invasive endoscopic intervention. Even if there is a genetic breakthrough which is able to identify a higher risk cohort, visualisation of the oesophagus with targeted biopsy of abnormal areas alongside a higher degree of assurance in dysplastic staging will still be required. A number of optical techniques have been and are still being investigated for these purposes. They offer the potential of detecting changes very early in the cancerous process, at the microstructural and molecular level, far earlier than the morphological changes that are needed for detection by traditional endoscopy. They offer additional information to differentiate dysplastic from non-dysplastic tissue and high grade from low grade dysplasia.

Optical diagnostic techniques, which are being used and are under development, are high resolution endoscopy, chromoendoscopy, narrow band imaging, optical coherence tomography, autofluorescence, immunophotodiagnostic endoscopy, confocal fluorescence microendoscopy, light scattering spectroscopy, Raman spectroscopy and infrared spectroscopy. No single modality has surged ahead and is able to satisfy all difficulties being faced and it is, thus, increasingly likely that a combination of techniques will be required to enable early disease detection and to reverse the dismal outcomes of oesophageal adenocarcinoma.

\section{Optical techniques}

\section{High resolution endoscopy (HRE)}

Traditional endoscopes are able to generate a 300,000 pixel image. High resolution endoscopes are able to generate images with greater than 1,000,000 pixels. Unsurprisingly, high resolution endoscopes have been shown to have a higher sensitivity than standard white light endoscopy for the detection of Barrett's oesophagus [23, 24], although the majority of evidence focuses on their use by expert endoscopists. The performance of and experience of the endoscopist contributes significantly to the detection of neoplasia, with mean inspection time per $\mathrm{cm}$ of Barrett's oesophagus having a significant impact [25]. The improved sensitivity is, by no means, perfect with only $79 \%$ of dysplasia detected [23], and with a substantial inter-observer variability identified $[23,26]$. Consensus guidelines have, nevertheless, recommended its use in expert centres [3] as it does go some way to improving the detection of abnormal areas. 


\section{Chromoendoscopy}

High resolution endoscopy has, in some studies, obtained better results when used in conjunction with chromoendoscopy [27] although this is not consistent [26]. Chromoendoscopy describes the exogenous administration of specialised dyes, including Lugols solution and methylene blue, onto the mucosal surface. They are typically sprayed onto the mucosal surface via a specifically designed catheter at the time of endoscopy. The stains enhance the detection of subtle mucosal irregularities that may otherwise be invisible [28].

Lugol's solution interacts with glycogen within minutes of its application in normal squamous epithelium resulting in a brown / black discoloration. In contrast, it does not stain columnar epithelium and, thus, can be useful in distinguishing squamous from columnar epithelium [28]. It has been shown to be effective in identifying early squamous cell cancer in the oesophagus and has been used for this application by Japanese endoscopists in patients who have previously had a diagnosis of head or neck cancer [29].

Methylene blue stains the intestinal metaplasia that defines Barrett's oesophagus and has an almost 100\% correlation with Barrett's epithelium [28]. Despite highlighting areas of Barrett's, the staining does not appear to aid the identification of areas of dysplasia. Acetic acid is another dye which enhances surface topography and has been shown, in some studies, to be superior to white light endoscopy in the localisation of dysplasia in Barrett's oesophagus [30].

Chromoendoscopy seems to be a sensible solution to improve the diagnostic yield of dysplasia, even if it is used as a temporary measure whilst other, better technologies are developed. The practise, however, has not been universally adopted primarily due to difficulties with spray application, time required for spray application and with operator subjectivity meaning that it is still far from ideal.

\section{Narrow band imaging}

Narrow band imaging enhances the resolution of the mucosal surface, aiding visualisation of surface irregularities as well as alterations in the vascular patterns. The mucosa is illuminated with both blue and green light wavelengths. The different wavelengths penetrate the tissue to different degrees resulting in increased resolution. Narrow band blue light displays the superficial capillary networks, due to its increased absorption by haemoglobin [31] and the alterations in vascular pattern that is seen in disease can be identified.

Initial reviews showed high sensitivities for distinguishing gastric mucosa from intestinal metaplasia [32] and subsequent work with further magnification demonstrated a high accuracy in identifying high grade dysplasia [32]. As with the other modalities discussed thus far, however, there is a high level of inter-observer variability in the detection of mucosal irregularities and, although this modality would be easy to integrate into standard endoscopy practises, its use is limited. $14 \%$ of endoscopists referring patients to a tertiary centre for further assessment of Barrett's oesophagus had used narrow band imaging [3].

\section{Optical coherence tomography}

Optical coherence tomography (OCT) is an imaging system analogous to ultrasonography in that it uses electromagnetic waves to form images based on the detection of reflected light, rather than reflected sound waves [33]. OCT systems have resolutions of 10-25 $\mu \mathrm{m}$, which enables the identification of microscopic features, including villi, glands, lymphatic aggregates and blood vessels [28].
Multiple studies have described the in vivo use of OCT as a screening tool for Barrett's oesophagus with the ability to distinguish between the appearances of squamous mucosa, gastric cardia, Barrett's oesophagus and adenocarcinoma [38-42]. The sensitivity for the differentiation between high grade dysplasia and adenocarcinoma was, however, only $83 \%$ with a specificity of $75 \%$ [42], with similar, if not worse results, in a subsequent study [43].

The identification of dysplasia, particularly high grade dysplasia, is the ultimate goal and the results thus far for OCT are, in the majority, not good enough, although a recent review found excellent diagnostic sensitivity and specificity for the detection of Barrett's oesophagus, although not necessarily of dysplasia [44]. This is likely to be linked to the subjective interpretation by the endoscopists, especially as this modality requires interpretation of histopathological changes. Its benefit does, however, lie in the fact that it provides cross-sectional imaging that permits assessment of the depth of invasion and can determine for which patients mucosal resection is a suitable option [34].

The speeds and modes of operation prohibit acquisition of data over large segments of the GI tract [35]. Spectrally encoded confocal endomicroscopy uses a different grating and a wavelength swept laser to image tissues at very high speeds [36]. In vivo experiments on anaesthetised living swine suggested that this technology could rapidly (in 2.1 minutes) provide large $(5 \mathrm{~cm}$ length) contiguous images of the oesophagus [35]. The technology had some technical flaws; however, it is an important step towards the illustrious wide-field scanning that is desperately required.

A novel approach has been the development of a swallowed tethered capsule endomicroscopy device which has been shown to image large portions of the oesophagus with agreement of $94 \%$ to manual tissue classification [37]. This form of technology could provide screening data, but patients would need further investigation, likely to be an endoscopy, to obtain tissue or to perform endomucosal resection.

\section{Autofluorescence}

All tissues produce autofluorescence when illuminated by ultraviolet $(<400 \mathrm{~nm})$ or short visible light $(400-550 \mathrm{~nm})$. The molecules responsible for this are termed fluorophores and the resultant autofluorescent signal is dependent on the concentration and distribution of the fluorophores. Normal, metaplastic and dysplastic tissue will have different autofluorescent spectra as malignant transformation alters the type, concentration and microdistribution of the constituent fluorophores [45].

Tissue autofluorescence can be performed relatively simply with the ability to sample wide areas of the mucosal surface. Different wavelengths penetrate and effectively interrogate the tissue to different depths, resulting in an image which provides clues as to the tissue topography and vasculature [46].

Studies using a variety of systems have had confounding results with some improving detection of dysplasia [47], and others being no better than traditional white light endoscopy [24,48]. A combined video endoscope system with both white light and autofluorescence did improve the detection of new areas of dysplasia [49], but was hampered by the inability to accurately distinguish inflamed tissue with that of dysplasia.

It may be overly hopeful to think that differences in autofluorescence patterns are specific enough to distinguish between low grade dysplasia, high grade dysplasia and adenocarcinoma. Alterations in 
autofluorescence would, however, direct the endoscopist to areas of interest which would be further assessed with a different diagnostic modality and/or biopsied. What would be ideal is a marker of dysplasia that has a unique fluorescent signal that would objectively identify the areas of the oesophagus that require further evaluation. No markers have, thus far, been identified; however, it may be that a molecular marker of the processes that are involved in dysplastic formation, such as apoptosis or cellular proliferation, can be found and that they have a unique autofluorescent signal.

Lipofuscin could be a candidate for this role (DaCosta; personal communication). Work looking at the colonic mucosa has shown that dysplastic epithelial cells had increased red autofluorescence intensity when compared to normal and hyperplastic cells and that this increase was due to the presence of large numbers of highly autofluorescent granules which were shown to be lysosomes [50]. Lipofuscin forms due to iron catalysed oxidation and polymerisation of protein and lipid residues [51]. These residues are cell fragments which are the result of apoptosis of epithelial cells.

If lipofuscin is able to be easily detected and enables differentiation between non-dysplastic and dysplastic tissue, and/or between different levels of dysplasia, or indeed if there are alternative markers that can do this, this would increase our ability to perform quick wide field scanning of the entire oesophagus and identify areas requiring magnified investigation.

\section{Immunophotodiagnostic endoscopy}

In a similar approach, studies have looked at combining chromogenic or fluorescent dyes with monoclonal antibodies that are specific for tumour-related antigens. The antibody would bind with the antigen and then emit fluorescence which is detectable and identify abnormal areas of the oesophagus. The clinical application of this has, thus far, had limited success which may be due to the lack of specific markers or the sub-optimal contrast differentiation between tissue types [46].

A glimmer of hope is lectins. Cell surface lectins are altered in the progression from Barrett's oesophagus to adenocarcinoma causing changes in binding patterns which can be identified [53]. This modality is highly attractive and as our understanding of the molecular basis of dysplasia and adenocarcinoma increases, further dysplasia associated markers may well be discovered.

\section{Confocal fluorescence microendoscopy}

Confocal fluorescence microendoscopy is an extension of autofluorescence. It images endogenous and exogenous fluorophores within the cells of the tissue sections [21] and provides a histological image of the tissue [52]. In ex vivo samples, dysplastic and non-dysplastic Barrett's oesophagus fluoresced mainly in the green spectrum with the main contribution from the mucosal layer. High grade dysplasia was able to be differentiated from that of non dysplastic Barrett's based on the assessment of the microstructural tissue changes [52]. This suggests that Barrett's oesophagus can be detected by mucosal autofluorescence [31], but the further delineation of dysplastic tissue requires the histological component of this modality which is a subjective measure.

\section{Spectroscopy}

Spectroscopy offers the ability to detect subtle biochemical changes in tissues and, thus, aids the differentiation of various tissue types, including that of dysplastic tissue. There is a substantial volume of work in the literature that confirms the ability of different forms of spectroscopy to differentiate between pathology states in a wide range of organ systems, including the oesophagus. Despite many years of evidence, however, there has been no move of spectroscopy into routine clinical practise.

Light scattering spectroscopy: Light scattering spectroscopy, also known as elastic scattering spectroscopy, provides microstructural information about tissue based on the reflectance of scattered white light. The backscattered light from epithelial nuclei can identify nuclear enlargement and crowding and this can be used to detect dysplasia with sensitivities and specificities of $>90 \%$ [54]. Subsequent studies have obtained reasonable results and have also been able to differentiate high risk sites from inflammation with sensitivities and specificities of $79 \%$ [55].

The main disadvantage of this tool, as with other methods of spectroscopy, is that it is unable to sample a large volume of the oesophagus. Other forms of spectroscopy provide greater information regarding tissue composition and, thus, it seems unlikely that light scattering spectroscopy will become a main stream tool to aid our identification of dysplasia.

Raman spectroscopy: Compared to the other spectroscopic techniques under investigation, Raman spectroscopy provides the most detailed information about the molecular composition of tissue. It relies on the inelastic scattering of monochromatic light, where the scattered photon's energy is altered by interaction with the molecular bonds present and results in a change in frequency. This information is extracted and enables the molecular composition of a tissue to be determined (Figure 2) [46].

The ability of Raman spectroscopy to discriminate between different pathology groups in a variety of ex vivo tissue groups has been well documented. In the oesophagus, in an analysis of snap-frozen biopsy samples, Raman analysis was able to discriminate between 8 different pathology groups, including subtypes of Barrett's oesophagus [56]. Fibre optic probes for Raman analysis via a needle probe or endoscope can enable tissue access for in vivo analysis [57].

From the turn of the century, a number of groups have trialled in vivo Raman probes. Work in 2011 demonstrated the identification of cancer in the oesophagus with a sensitivity of $91 \%$ and a specificity of $94 \%$ and, importantly, with an acquisition time of 0.4-0.5 seconds [58]. Dysplastic change was, however, not differentiated.

Despite rapid spectral acquisition times, a major limitation of Raman probe measurement is that only a small volume of mucosa

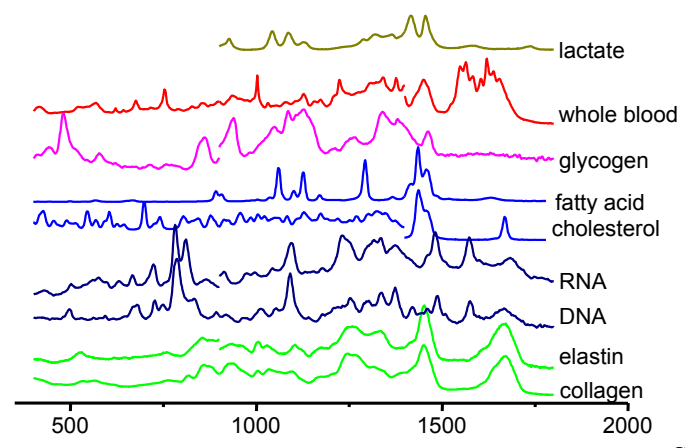

Wavenumber $\left(\mathrm{cm}^{-1}\right)$

Figure 2. Examples of Raman spectra measured from a variety of human molecular constituents. Characteristic Raman peaks are seen for each substance at reproducible positions. 
can be interrogated at one time. This prohibits its use as a wide field scanning modality, but would make it an ideal instrument for point measurements to aid in vivo diagnosis. Raman probes can, and have been, used in conjunction with other modalities which are able to scan wide areas of the oesophagus to overcome this barrier and this is discussed later. The narrow field imaging of Raman would, however, be well suited to other in vivo applications, such as real time targeted therapy during endomucosal resection to establish resection margin clearance [59], although it would need to be able to distinguish areas of dysplasia as well as adenocarcinoma.

Rather than replacing the gold standard of histopathology for diagnosis, Raman spectroscopy could be utilised in the laboratory for the analysis of ex vivo samples to aid diagnosis, particularly when there is a lack of consensus regarding the presence and/or grade of dysplasia. Rapid mapping of tissue sections using Raman has the potential to be used as an automated histopathology tool. It has been shown that $2 \mathrm{~mm}$ diameter sections can be mapped over a time scale of 30-90 minutes, and that this was sufficient to discriminate pathology [60]. This would provide an additional tool for the pathologist when analysing biopsy samples. Current work is focused on investigating system transferability when using Raman to map oesophageal tissue sections to facilitate this function [61].

Fourier-transform infra-red spectroscopy: Infrared spectroscopy exploits the feature that tissue absorbs light at characteristic wavelengths which are determined by the vibrational motions of covalently bonded atoms. FTIR is able to collate a rapid molecular fingerprint of tissue with information regarding different tissue constitutes such as DNA and glycogen. The pattern of the spectra generated is sensitive to small changes in multiple tissue constituents and, therefore, is different for the different pathologies [62]. For example, increased DNA and glycoprotein content predicts the presence of dysplasia in Barrett's oesophagus and this is consistent with histopathology [63].

The development of adenocarcinoma follows a well established pattern which begins prior to any morphological changes. Gene mutation is the primary event, followed by changes in the biomolecules of the tissue. FTIR has the potential to detect these changes and potentially identify changes prior to those described as precancerous, i.e.,: at the earliest stage of dysplastic change. As with Raman, however, this is not currently a method whereby the entire oesophagus can be screened with FTIR to identify these areas. An additional hindrance of IR is the strong influence of water with peaks overlapping with the Amide I band of proteins, affecting the diagnostic ability of this technique [64]. Fibre-optic evanescent wave spectroscopy (FEWS)FTIR with endoscope compatible fibre-optic silver halide probes has been shown to be feasible, although the development of in vivo tissue drying is likely to improve results [65].

The role of FTIR is, therefore, likely to be complimentary to Raman in aiding histopathological diagnosis of biopsied material.

\section{The way ahead}

An ideal diagnostic model to identify dysplasia in the oesophagus would enable real time scanning of a vast area of mucosa, ideally the entire oesophagus. It would be able to accurately identify areas of low grade dysplasia, high grade dysplasia and adenocarcinoma and differentiate these from active inflammation and other pathologies with a high degree of specificity. It would be easy to set up and use and be cost effective. Unfortunately it does not exist.

What then is the solution? A multi-modal approach is needed to tackle the two predominant problems that face the diagnosis of dysplasia in Barrett's oesophagus.

A wide field detection is required that is able to assess the whole oesophagus and identify areas requiring more specific review. Autofluorescence would be simple and easy to employ and if a marker of dysplasia could be identified then this would make this modality the principal choice. A narrow field modality would then be utilised at the same endoscopy to further delineate these areas. The narrow field modalities, predominantly those of Raman and FTIR, provide additional and complimentary information to that of histopathology. Using all modalities in conjunction will provide the greatest information regarding the disease state of the tissue, increasing the accuracy of diagnosis and providing detailed information regarding the cancerous changes that take place. It will only be with complimentary working with pathology, rather than an attempt to replace them, that we will develop the greatest understanding of the changes that occur in cancerous change in the oesophagus.

Evidence is starting to filter in of the benefit of a multimodal approach. For example, the combination of Raman spectroscopy and optical coherence tomography has been shown to be superior to either modality in isolation at discriminating between colonic adenocarcinoma and normal colon [66]. A dual probe combining fluorescence and Raman spectroscopy was shown to have good correlation with histopathology when used for ex vivo melanocytic lesions [67] and a recent study using the same two modalities in the same probe demonstrated the potential of this technology to be used in vivo [68]. The combination of autofluorescence and Raman has taken an early lead in the ideal modality combination as the two provide complimentary information.

\section{Conclusion}

There is still a long way to go. Each modality needs to be perfected and translated into clinical care and then the ideal combination needs to be selected. This may, however, not be the same for every patient and the advantages of each may alter depending on the patient. Nevertheless, the incidence of both Barrett's oesophagus and adenocarcinoma are climbing and the requirement for new and improved diagnostic tools is greater than ever.

\section{References}

1. CR UK (2013) Cancer Key Facts. Cancer Research UK.

2. BARRETT NR (1950) Chronic peptic ulcer of the oesophagus and 'oesophagitis'. Br J Surg 38: 175-182. [Crossref]

3. Bennett C, Moayyedi P, Corley DA et al. (2015) BOB CAT: a Large-Scale Review and Delphi Consensus for Management of Barrett's Esophagus with No Dysplasia, Indefinite for, or Low-Grade Dysplasia. Am J Gastroenterol 110: 662-682. [Crossref]

4. Fléjou JF (2005) Barrett's oesophagus: from metaplasia to dysplasia and cancer. Gut 54 Suppl 1: i6-12. [Crossref]

5. Duggan C, Onstad L, Hardikar S, Blount PL, Reid BJ, et al. (2013) Association between markers of obesity and progression from Barrett's esophagus to esophageal adenocarcinoma. Clin Gastroenterol Hepatol 11: 934-943. [Crossref]

6. Duits LC, Phoa KN, Curvers WL, Ten Kate FJ, Meijer GA, et al. (2015) Barrett's oesophagus patients with low-grade dysplasia can be accurately risk-stratified after histological review by an expert pathology panel. Gut 64: 700-706. [Crossref]

7. Phoa KN, van Vilsteren FG, Weusten BL, Bisschops R, Schoon EJ, et al. (2014) Radiofrequency ablation vs endoscopic surveillance for patients with Barrett esophagus and low-grade dysplasia: a randomized clinical trial. JAMA 311: 1209-1217. [Crossref]

8. Heitmiller RF, Redmond M, Hamilton SR (1996) Barrett's esophagus with highgrade dysplasia. An indication for prophylactic esophagectomy. Ann Surg 224: 66-71. [Crossref] 
9. Falk GW, Rice TW, Goldblum JR, Richter JE. (1999) Jumbo biopsy forceps still misses unsuspected cancer in Barrett's oesophagus with high-grade dysplasia. Gastrointestinal Endoscopy 49: 170-176. [Crossref]

10. Chadwick G, Groene O, Hoare J, Hardwick RH, Riley S, et al. (2014) A populationbased, retrospective, cohort study of esophageal cancer missed at endoscopy. Endoscopy 46: 553-560. [Crossref]

11. WHO (2010) Classification of Tumours of the Digestive System, 4th edn ed. IARC Press: Lyon.

12. Lee YC, Cook MB, Bhatia S, Chow WH, El-Omar EM, et al. (2010) Interobserver reliability in the endoscopic diagnosis and grading of Barrett's esophagus: an Asian multinational study. Endoscopy 42: 699-704. [Crossref]

13. Kerkhof M, Van Dekken H, Steverberg EW, Meijer GA, Mulder AH, et al. (2007) Grading of dysplasia in Barrett's oesophagus: substantial interobserver variation between general and gastrointestinal pathologists. Histopathology 50: 920-927. [Crossref]

14. Gaddam S, Mathur SC, Singh M, Arora J, Wani SB, et al. (2011) Novel probe-based confocal laser endomicroscopy criteria and interobserver agreement for the detection of dysplasia in Barrett's esophagus. Am J Gastroenterol 106: 1961-1969. [Crossref]

15. Wang JS, Guo M, Montgomery EA, Thompson RE, Cosby H, et al. (2009) DNA promoter hypermethylation of $\mathrm{p} 16$ and APC predicts neoplastic progression in Barrett's esophagus. Am J Gastroenterol 104: 2153-2160. [Crossref]

16. Hardwick RH, Shepherd NA, Moorghen M, Newcomb PV, Alderson D (1994) Adenocarcinoma arising in Barrett's oesophagus: evidence for the participation of $\mathrm{p} 53$ dysfunction in the dysplasia/carcinoma sequence. Gut 35: 764-768. [Crossref]

17. Kastelein F, Biermann K, Steyerberg EW, Verheij J, Kalisvaart M, et al. (2013) Aberrant p53 protein expression is associated with an increased risk of neoplastic progression in patients with Barrett's oesophagus. Gut 62: 1676-1683. [Crossref]

18. Bennett C, Vakil N, Bergman J, Harrison R, Odze R et al. (2012) Consensus Statements for Management of Barrett's Dysplasia and Early-Stage Esophageal Adenocarcinoma, Based on a Delphi Process. Gastroenterology 143: 336-346. [Crossref]

19. Bhat S, Coleman HG, Yousef F, Johnston BT, McManus DT, et al. (2011) Risk of malignant progression in Barrett's esophagus patients: results from a large populationbased study. J Natl Cancer Inst 103: 1049-1057. [Crossref]

20. Old O, Moayyedi P, Love S, Roberts C, Hapeshi J, et al. (2015) Barrett's Oesophagus Surveillance versus endoscopy at need Study (BOSS): protocol and analysis plan for a multicentre randomised controlled trial. J Med Screen 22: 158-164. [Crossref]

21. Bhat SK, McManus DT, Coleman HG, Johnston BT, Cardwell CR, et al. (2015) Oesophageal adenocarcinoma and prior diagnosis of Barrett's oesophagus: a population-based study. Gut 64: 20-25. [Crossref]

22. El-Serag HB, Naik AD, Duan Z, Shakhatreh M, Helm A, et al. (2015) Surveillance endoscopy is associated with improved outcomes of oesophageal adenocarcinoma detected in patients with Barrett's oesophagus. Gut [Crossref]

23. Kara MA, Peters FP, Rosmolen WD, Krishnadath KK, ten Kate FJ, et al. (2005) Highresolution endoscopy plus chromoendoscopy or narrow-band imaging in Barrett's esophagus: a prospective randomized crossover study. Endoscopy 37: 929-936. [Crossref]

24. Kara MA, Smits ME, Rosmolen WD, Bultje AC, Ten Kate FJ, et al. (2005) A randomised crossover study comparing light-induced fluorescence endoscopy with standard videoendoscopy for the detection of early neoplasia in Barrett's oesophagus. Gastrointest Endosc 61: 671-678. [Crossref]

25. Gupta N, Gaddam S, Wani SB, Bansal A, Rastogi A, Sharma P (2011) Longer Barrett's inspection time (Bit) is associated with a higher detection rate of high grade dysplasia (HGD) and early esophageal adenocarcinoma (EAC). Gastroenterology 1: S198-S199. [Crossref]

26. Curvers W, Baak L, Kiesslich R, Van Oijen A, Rabenstein T, et al. (2008) Chromoendoscopy and narrow-band imaging compared with high-resolution magnification endoscopy in Barrett's esophagus. Gastroenterology 134: 670-679. [Crossref]

27. Gill RS, Singh R (2012) Endoscopic imaging in Barrett's esophagus: current practice and future applications. Ann Gastroenterol 25: 89-95. [Crossref]

28. DaCosta RS, Wilson BC, Marcon NE (2003) Photodiagnostic techniques for the endoscopic detection of premalignant gastrointestinal lesions. Digestive Endoscopy $15: 153-173$

29. Ina H, Shi buya H, Ohashi I, Kitagawa M (1994) The frequency of a concomitant early esophageal cancer in male patients with oral and oropharyngeal cancer: Screening results using Lugol dye endoscopy. Cancer 73: 2038-2041. [Crossref]

30. Longcroft-Wheaton G, Kandaswamy P, Bhandari P (2011) Acetic acid enhanced chromoendoscopy is more cost effective than protocol guided biopsies in a high risk Barrett's population: results from a large prospective series. Gut 60: 32-33

31. Kara MA, Ennahachi M, Fockens P, ten Kate FJ, Bergman JJ (2006) Detection and classification of the mucosal and vascular patterns (mucosal morphology) in Barrett's esophagus by using narrow band imaging. Gastrointest Endosc 64: 155-166. [Crossref]

32. Curvers WL, Van den Broek FJ, Reitsma JB, Dekker E, Bergman JJ (2009) Systematic review of narrow-band imaging for the detection and differentiation of abnormalities in the esophagus and stomach. Gastrointest Endosc 69: 307-317. [Crossref]

33. Filip M, Iordache S, SÄ fftoiu A, Ciurea T (2011) Autofluorescence imaging and magnification endoscopy. World J Gastroenterol 17: 9-14. [Crossref]

34. Lightdale CJ (2013) Optical coherence tomography in Barrett's esophagus. Gastrointest Endosc Clin N Am 23: 549-563. [Crossref]

35. Kang D, Schlachter SC, Carruth RW, Kim M, Wu T, et al. (2014) Comprehensive confocal endomicroscopy of the esophagus in vivo. Endosc Int Open 2 : E135-140. [Crossref]

36. Tearney GJ, Webb RH, Bouma BE (1998) Spectrally encoded confocal microscopy Opt Lett 23: 1152-1154. [Crossref]

37. Ughi GJ, Gora MJ, Swager AF, Soomro A, Grant C, et al. (2016) Automated segmentation and characterisation of esophageal wall in vivo by tethered capsule optical coherence tomography endomicroscopy. Biomedical Optics Express 7: 409419. [Crossref]

38. Zuccaro G, Gladkova N, Vargo J, Feldchtein F, Zagaynova E, et al. (2001) Optica coherence tomography of the esophagus and proximal stomach in health and disease. Am J Gastroenterol 96: 2633-2639. [Crossref]

39. Poneros JM, Brand S, Bouma BE, Tearney GJ, Compton CC, Nishioka NS (2001) Diagnosis of specialised intestinal metaplasia by optical coherence tomography. Gastroenterolgy 120: 7-12. [Crossref]

40. Li XD, Boppart SA, Van Dam J, Mashimo H, Mutinga M, et al. (2000) Optica coherence tomography: advanced technology for the endoscopic imaging of Barrett's esophagus. Endoscopy 32: 921-930. [Crossref]

41. Evans JA, Nishioka NS (2005) The use of optical coherence tomography in screening and surveillance of Barrett's esophagus. Clin Gastroenterol Hepatol 3: S8-11. [Crossref]

42. Evans JA, Poneros JM, Bouma BE, Bressner J, Halpern EF, et al. (2006) Optica Coherence Tomography to Identify Intramucosal Carcinoma and High-Grade Dysplasia in Barrett's Esophagus. Clinical Gastroenterology and Hepatology 4: 38-43. [Crossref]

43. Evans JA, Bouma BE, Bressner J, Shishkov M, Lauwers GY, et al. (2007) Identifying Intestinal Metaplasia at the Squamocolumnar Junction by using Optical Coherence Tomography. Gastrointestinal Endoscopy 65: 50-56. [Crossref]

44. Robles LY, Singh S, Fisichella PM (2015) Emerging enhanced imaging echnologies of the esophagus: spectroscopy, confocal laser endomicroscopy and optical coherence tomography. J Surg Research 195: 502-514. [Crossref]

45. Kara M, DaCosta RS, Wilson BC, Marcon NE, Bergman J (2004) Autofluorescencebased detection of early neoplasia in patients with Barrett's esophagus. Dig Dis 22: 134-141. [Crossref]

46. Dacosta RS, Wilson BC, Marcon NE (2006) Spectroscopy and fluorescence in esophageal diseases. Best Pract Res Clin Gastroenterol 20: 41-57. [Crossref]

47. Haringsma J, Poley J, Blok P, et al. (2005) Detection of intraepithelial neoplasia in Barrett's esophagus using autofluorescence endoscopy. DDW

48. Egger K, Werner M, Meining A, Ott R, Allescher HD, et al. (2003) Biopsy surveillance is still necessary in patients with Barrett's oesophagus despite new endoscopic imaging techniques. Gut 52: 18-23. [Crossref]

49. Kara MA, Peters FP, Ten Kate FJ, Van Deventer SJ, Fockens P, et al. (2005) Endoscopic video autofluorescence imaging may improve the detection of early neoplasia in patients with Barrett's esophagus. Gastrointest Endosc 61: 679-685. [Crossref]

50. DaCosta RS, Andersson H, Cirocco M, Marcon NE, Wilson BC (2005) Autofluorescence Characterisation of Isolated Whole Crypts and Primary Cultured Human Epithelial Cells from Normal, Hyperplastic, and Adenomatous Colonic Mucosa. Journal of Clinical Pathology 58: 766-774. [Crossref]

51. Ghadially FN, Walley VM (1994) Melanoses of the gastrointestinal tract. Histopathology 25: 197-207. [Crossref] 
52. Kara MA, DaCosta RS, Streutker CJ, Marcon NE, Bergman JJ, et al. (2007) Characterization of tissue autofluorescence in Barrett's esophagus by confocal fluorescence microscopy. Dis Esophagus 20: 141-150. [Crossref]

53. Bird-Lieberman EL, Neves AA, Lao-Sirieix P, O’Donovan M, Novelli M, et al. (2012) Molecular imaging using fluorescent lectins permits rapid endoscopic identification of dysplasis in Barrett's esophagus. Nature Medicine 18: 315-322. [Crossref]

54. Wallace MB, Perelman LT, Backman V, Crawford JM, Fitzmaurice M, et al. (2000) Endoscopic detection of dysplasia in patients with Barrett's esophagus using light scattering spectroscopy. Gastroenterology 119: 677-682. [Crossref]

55. Lovat LB, Johnson K, Mackenzie GD, Clark BR, Novelli MR, et al. (2006) Elastic scattering spectroscopy accurately detects high grade dysplasia and cancer in Barrett's oesophagus. Gut 55: 1078-1083. [Crossref]

56. Kendall C, Stone N, Shepherd N, Geboes K, Warren B, et al. (2003) Raman spectroscopy, a potential tool for the objective identification and classification of neoplasia in Barrett's oesophagus. J Pathol 200: 602-609. [Crossref]

57. Wong Kee Song LM, Wilson BC (2005) Endoscopic detection of early upper GI cancers. Best Pract Res Clin Gastroenterol 19: 833-856. [Crossref]

58. Bergholt MS, Zheng W, Lin K, Ho KY, Teh M, et al. (2011) In vivo diagnosis of esophageal cancer using image-guided Raman Endoscopy and Biomolecular Modelling. Technology in Cancer 10: 103-112. [Crossref]

59. Almond LM, Hutchings J, Shepherd N, Barr H, Stone N, et al. (2011) Raman spectroscopy: a potential tool for early objective diagnosis of neoplasia in the oesophagus. J Biophotonics 4: 685-695. [Crossref]

60. Hutchings J, Kendall C, Shepherd N, Barr H, Stone N (2010) Evaluation of linear discriminant analysis for automated Raman histological mapping of esophageal highgrade dysplasia. J Biomed Opt 15: 066015. [Crossref]

61. Isabelle M, Dorney J, Lewis A (2016) Multi-centre Raman spectral mapping of oesophageal cancer tissues: a study to assess system transferability. Faraday Discuss.

62. Wang TD, Triadafilopoulos G, Crawford JM, Dixon LR, Bhandari T, et al. (2007) Detection of endogenous biomolecules in Barrett's esophagus by Fourier transform infrared spectroscopy. Proc Natl Acad Sci U S A 104: 15864-15869. [Crossref]

63. Bancroft JD, Gamble M (2002) Theory and Practice of Histological Techniques (Churchill-Livingstone, New York). 5th Edition.

64. Zhao R, Quaroni L, Casson AG. (2009) Fourier transform infrared (FTIR) spectromicroscopic characterisation of stem-like cell populations in human esophageal normal and adenocarcinoma cell lines. Analyst 135: 53-61. [Crossref]

65. Mackanos MA, Contag CH (2010) Fiber-optic probes enable cancer detection with FTIR spectroscopy. Trends Biotechnol 28: 317-323. [Crossref]

66. Ashok PV, Praveen BB, Bellini N, Riches A, Dholakia K, Herrington CS. (2013) Multimodal approach using Raman spectroscopy and optical coherence tomography for the discrimination of colonic adenocarcinoma from normal colon. Biomedical Optics Express 4: 2179-2186. [Crossref]

67. Cicchi R, Cosci A, Rossari S, Kapsokalyvas D, Baria E, et al. (2014) Combined fluorescence-Raman spectroscopic setup for the diagnosis of melanocytic lesions. Journal of Biophotonics 7: 86-95. [Crossref]

68. Dochow S, Ma D, Latka I, Bocklitz T, Hartl B, et al. (2015) Combined fiber probe for fluorescence lifetime and Raman spectroscopy. Anal Bioanal Chem 407: 8291-8301. [Crossref]

Copyright: (2016 Upchurch E. This is an open-access article distributed under the terms of the Creative Commons Attribution License, which permits unrestricted use, distribution, and reproduction in any medium, provided the original author and source are credited. 